\title{
Genome wide CNV analysis reveals additional variants associated with milk production traits in Holsteins
}

Lingyang Xu ${ }^{1,2}$, John B Cole ${ }^{1}$, Derek M Bickhart ${ }^{1}$, Yali Hou ${ }^{3}$, Jiuzhou Song ${ }^{2}$, Paul M VanRaden ${ }^{1}$, Tad S Sonstegard ${ }^{1}$, Curtis P Van Tassell ${ }^{1}$ and George E Liư ${ }^{1 *}$

\begin{abstract}
Background: Milk production is an economically important sector of global agriculture. Much attention has been paid to the identification of quantitative trait loci (QTL) associated with milk, fat, and protein yield and the genetic and molecular mechanisms underlying them. Copy number variation (CNV) is an emerging class of variants which may be associated with complex traits.

Results: In this study, we performed a genome-wide association between CNVs and milk production traits in 26,362 Holstein bulls and cows. A total of 99 candidate CNVs were identified using Illumina BovineSNP50 array data, and association tests for each production trait were performed using a linear regression analysis with PCA correlation. A total of 34 CNVs on 22 chromosomes were significantly associated with at least one milk production trait after false discovery rate (FDR) correction. Some of those CNVs were located within or near known QTL for milk production traits. We further investigated the relationship between associated CNVs with neighboring SNPs. For all 82 combinations of traits and CNVs (less than $400 \mathrm{~kb}$ in length), we found 17 cases where CNVs directly overlapped with tag SNPs and 40 cases where CNVs were adjacent to tag SNPs. In 5 cases, CNVs located were in strong linkage disequilibrium with tag SNPs, either within or adjacent to the same haplotype block. There were an additional 20 cases where CNVs did not have a significant association with SNPs, suggesting that the effects of those CNVs were probably not captured by tag SNPS.
\end{abstract}

Conclusion: We conclude that combining CNV with SNP analyses reveals more genetic variations underlying milk production traits than those revealed by SNPs alone.

Keywords: Copy number variation (CNV), dPTA, Association, Milk production traits

\section{Background}

Milk production is an economically important sector of global agriculture and much attention has been paid to improve milk performance-related traits in cattle. Various methods have been employed to identify significant genetic markers for milk production. These methods include quantitative trait loci (QTL) mapping with different mapping designs and genome-wide association studies with a variety of statistical tests. Many QTL related to milk production traits have been reported using

\footnotetext{
* Correspondence: George.Liu@ars.usda.gov

'Animal Genomics and Improvement Laboratory, BARC, USDA-ARS, Beltsville, Maryland 20705, USA

Full list of author information is available at the end of the article
}

different populations and DNA markers, such as microsatellite [1-4] and SNPs [5-11]. The identification of QTL and investigation of genetic and molecular mechanisms underlying those QTL may result in more efficient animal selection and increased rates of genetic progress. However, most of these cattle QTL studies did not identify the casual variant, which is useful information for breeding applications to avoid losses in accuracy because of recombination between associated QTL markers and the actual quantitative trait nucleotide (QTN). Only a few casual mutations within genes of known function, such as DGAT [3,12,13], ABCG [4] and GRH [14,15], have been identified with their large effects on milk production validated. Additionally, most of those GWAS studies 
concluded that SNP may only explain a small portion of genetic variance. Alternative frameworks to explain the missing heritability of complex traits were proposed [16].

Genomic structural variants are comprised mainly of copy number variations ( $\mathrm{CNVs})$ in the form of large-scale insertions and deletions, as well as inversions and translocations [17]. Compared to SNPs, CNVs involve more genomic sequence and have potentially greater effects, including changing gene structure and dosage, alternating gene regulation and exposing recessive alleles [18]. Human and mouse studies have found that CNVs capture 18 to $30 \%$ of the genetic variation in gene expression $[19,20]$. Those CNVs were shown to be important in both normal phenotypic variability and disease susceptibility. In livestock, most CNV studies have used limited CNV detection methods, including CGH arrays, SNP arrays, and next generation sequencing [21-31]. Our previous studies have indicated that some CNVs could be associated with resistance or susceptibility to gastrointestinal nematodes in Angus cattle [32] and residual feed intake in Holstein cows [33]. Moreover, Glick et al. identified a CNV associated with fertility in Israeli Holsteins [34]. A recent study reported a $660 \mathrm{~kb}$ deletion with antagonistic effects on fertility and milk production in Nordic Red cattle [35]. Kadri et al. previously reported linkage disequilibrium (LD) between one deletion and its neighboring SNPs in Holsteins cattle [36]. However, no study has reported about genome wide CNV association directly with milk production traits. Furthermore, no systematic study of the relationship between CNVs and SNPs in the bovine genome has been published.

In this study, we reported a systematic CNV association analysis with milk production traits in 26,362 US Holsteins. Thirty-four CNVs have been identified as significantly associated with milk production traits using an association test, and most of them overlap known QTL. Haplotype analysis for associated CNVs and neighboring SNPs produced further evidence that CNVs provide additional information that is not captured by SNPs alone. Therefore, CNVs could be utilized as additional molecular markers for use in genetic improvement programs.

\section{Methods}

\section{Samples}

Holstein bulls and cows (26,362 samples) were genotyped using the Illumina BovineSNP50 array version 1 (Illumina Inc., San Diego, CA). Genotypes of those animals have been included in the routine genomic evaluation program for the United States and Canada since 2009 [37,38]. The main source of extracted DNA for bulls was semen from the Cooperative Dairy DNA Repository and from the National Center for Genetic Resources Preservation, ARS, USDA (Fort Collins, CO). The research did not involve any experiment on animals and for this reason no ethics approval was necessary.

\section{Phenotypic and APTA values}

Traditional predicted transmitting abilities (PTAs) for five production traits, including milk yield (MY), fat yield (FY), protein yield (PY), fat percentage (FP), and protein percentage (PP), were calculated by USDA ARS AIPL (Beltsville, MD). Those PTA are predicted additive genetic effects after removing fixed non-genetic effects, and the reliabilities of the PTA were used to quantify the amount of information available for different individuals $[39,40]$. De-regressed PTAs (dPTA) were computed as in Garrick et al. [40] by dividing PTA by their squared reliability $\left[\mathrm{dPTA}=\mathrm{PTA} /(\text { reliability })^{2}\right]$. The dPTA were used as the phenotypes for genome-wide association studies.

\section{CNV segmentation and genotyping}

The intensity data of 56,947 SNP probes were generated by Illumina BovineSNP50 arrays. We imported Log R Ratios (LRR) from the GenomeStudio software into Golden Helix SNP \& Variation Suite (SVS) 7.7 (Golden Helix Inc., Bozeman, MT, USA) using its DSF Export Plug-In 4.1.

A total of 48,669 SNPs were mapped onto the Bos taurus genome assembly UMD 3.1 (https://ccb.jhu.edu/ bos_taurus_assembly.shtml) within 29 autosomes.

To normalize the LRR, we used the default GC correlation file (GC Reference bos_taurus_UMD3.1.gc_digest. dsf) to correct for the waviness contributed by GC content. We then utilized the copy number analysis module (CNAM) under the multivariate option to segment chromosomes with a maximum of 20 segments per window, a minimum of 3 markers per segment, and a significance level of $\mathrm{p}=0.01$ for pairwise permutations $(\mathrm{n}=1,000)$ as described previously [41].

\section{PCA-corrected association testing}

In Golden Helix SVS 7.7, a linear regression under the additive genetic model was employed to identify $\mathrm{CNVs}$ associated with each production trait with the option of Full Scan Permutations (10,000 permutations). We used the principal component analysis (PCA) option to correct batch effects/stratification of the test input data. Significant CNVs were counted at the significance level of (p-value < 0.05) after FDR correction.

\section{Association tests based on SNPs}

Association tests were carried out using the linear model plugin of SVS 7.7 software with PCA correction. Significant SNPs were detected when their adjusted $\mathrm{p}$-values passed the threshold of $\mathrm{p}<1 \times 10^{-8}$ after FDR correction.

\section{Haplotype block analysis}

To investigate linkage disequilibrium (LD) patterns in the regions containing associated $\mathrm{CNVs}$, pairwise $\mathrm{LD}$ 
statistics D' and $\mathrm{r}^{2}$ were calculated using Haploview (Version 4.2) [42] and the LD blocks were defined by the criteria of Gabriel et al. [43]. Qanbari et al. [44] presented a linkage disequilibrium (LD) map for Holsteins based on the same Bovine SNP50 array. Based on their maximum haplotype block length $(1.26 \mathrm{Mb})$, the regions considered for LD analysis were extended 25 SNPs on the both upstream and downstream directions of each $\mathrm{CNV}$ (i.e., $1.26 \mathrm{Mb}$ /average marker spacing of $50 \mathrm{~kb}$ ).

Relationship between significantly associated CNVs and significantly associated SNPs

We classified all 82 significant combinations of traits and $\mathrm{CNVs}$ (less than $400 \mathrm{~kb}$ in length and $\mathrm{p}$ values $<0.05$ after
FDR correction as shown in bold and italic in Table 1) in the following way. First, when a significant SNP directly overlapped with a CNV by genomic coordinate, we called the situation as "IN". If a SNP was directly adjacent to a CNV, we called it "IN". When a SNP was the second SNP next to a CNV, we called it "IN**". Any SNPs beyond the neighboring 2 positions of a $\mathrm{CNV}$ were not considered in this comparison. We then evaluated the linkage relationship between CNVs and neighboring SNPs. When a CNV was in the same haploblock with at least one significant SNP, we called it "LD". When a CNV was adjacent to a haploblock which contains at least one significant SNP, we called it "LD". In contrast, when a CNV was in a haploblock which contained no significant SNP, we called it

Table 1 Relationship classification between trait associated CNVs and their neighboring SNPs for 82 combinations of trait and CNVs

\begin{tabular}{|c|c|c|c|c|c|c|c|c|c|c|c|c|}
\hline \multirow[t]{2}{*}{ CNV\# } & \multicolumn{5}{|c|}{$P$ value after FDR correction } & \multicolumn{5}{|c|}{ Tagged by SNPs } & \multirow[t]{2}{*}{ Breakpoint } & \multirow{2}{*}{$\begin{array}{l}\text { PennCNI } \\
\text { Support }\end{array}$} \\
\hline & MY & FY & PY & $\mathrm{FP}$ & PP & MY & FY & PY & FP & PP & & \\
\hline 1 & $2.56 E-06$ & $2.12 E-08$ & 0.0246 & 0.0657 & $3.96 E-21$ & $\mathrm{IN}^{*}$ & $\mathrm{IN}^{*}$ & $\mathrm{IN}^{*}$ & & NN & & \\
\hline 2 & $8.53 E-07$ & $1.32 E-07$ & 0.0020 & 0.8913 & $1.46 E-09$ & IN & IN & IN & & NN & & Yes \\
\hline 3 & 0.0810 & 0.1375 & 0.9468 & 0.6499 & $1.32 E-32$ & & & & & $\mathrm{IN}^{*}$ & & \\
\hline 4 & $1.26 E-09$ & $1.99 E-08$ & $4.06 E-09$ & 0.1334 & 0.0756 & $\mathrm{IN}^{* *}$ & $\mathrm{IN}^{* *}$ & $\mathrm{IN}^{* *}$ & & & & Yes \\
\hline 5 & 0.2506 & 0.0473 & 0.2410 & 0.0758 & 0.0008 & & $1 N^{*}$ & & & $\mathbb{I N}^{*}$ & Yes & Yes \\
\hline 6 & 0.0008 & $1.91 E-06$ & $4.95 E-05$ & 0.0004 & $6.95 E-22$ & NN & NN & IN & NN & NN & & Yes \\
\hline 7 & 0.0020 & 0.0001 & 0.0418 & 0.2851 & $1.38 E-05$ & $I^{* *}$ & $\mathrm{IN}^{* *}$ & NN & & $\mathrm{IN}^{* *}$ & & Yes \\
\hline 8 & $9.03 E-10$ & $5.38 E-10$ & $1.61 E-06$ & 1.0000 & $9.35 E-05$ & $\mathrm{IN}^{*}$ & $\mathrm{IN}^{*}$ & $\mathrm{IN}^{*}$ & & $\mathrm{IN}^{*}$ & & Yes \\
\hline 9 & 0.0005 & $2.50 E-06$ & 0.2701 & 0.0049 & $9.47 E-18$ & $\mathrm{IN}^{* *}$ & $I^{* *}$ & & NN & IN & & \\
\hline 10 & $9.29 E-12$ & $8.38 E-12$ & $2.23 E-07$ & 1.0000 & 0.0997 & IN & IN & $\mathrm{IN}^{*}$ & & & & \\
\hline 11 & $3.81 E-05$ & $6.52 E-05$ & 0.0345 & 0.7610 & 0.0037 & $\mathrm{IN}^{*}$ & $\mathrm{IN}^{*}$ & $\mathrm{IN}^{*}$ & & IN & Yes & Yes \\
\hline 12 & 0.0006 & 0.1336 & 0.5275 & $3.70 E-09$ & $1.52 E-22$ & $\mathrm{IN}^{*}$ & & & $\mathrm{IN}^{*}$ & NN & & Yes \\
\hline 14 & 0.1484 & 0.5341 & 0.7490 & 0.0700 & 0.0371 & & & & & $\mathrm{IN}^{*}$ & Yes & \\
\hline 16 & 0.2552 & 0.8739 & 0.0352 & 0.0033 & 0.2416 & & & NN & $\mathrm{LD}^{*}$ & & & Yes \\
\hline 17 & $6.96 E-07$ & $2.87 E-06$ & $2.99 E-05$ & 0.4144 & 0.9401 & $\mathrm{IN}^{*}$ & $1 N^{* *}$ & $\mathrm{IN}^{*}$ & & & & Yes \\
\hline 18 & 0.0890 & $2.02 E-05$ & 0.0062 & $1.79 E-13$ & $6.21 E-15$ & & LD & LD & $I N^{*}+L D$ & $\mathrm{IN}^{*}$ & Yes & Yes \\
\hline 19 & 0.0032 & $3.53 E-05$ & 0.2698 & 0.0061 & 0.0035 & $\mathrm{IN}^{*}$ & $\mathrm{IN}^{*}$ & & $\mathrm{IN}^{*}$ & IN & Yes & \\
\hline 20 & 0.9468 & 0.8614 & 0.6384 & 1.0000 & 0.0286 & & & & & NN & & \\
\hline 21 & 0.0798 & 0.1692 & 0.5656 & 0.3360 & 0.0433 & & & & & $I N+L D$ & & Yes \\
\hline 22 & 0.6780 & 0.4652 & 0.3753 & 0.9048 & 0.0005 & & & & & NN & Yes & Yes \\
\hline 23 & 0.0065 & 0.0209 & 0.0008 & 0.5674 & $7.60 E-05$ & NN & $\mathrm{IN}^{* *}$ & $\mathrm{IN}^{* *}$ & & NN & & \\
\hline 24 & 0.0616 & 0.0844 & 0.6569 & 0.8919 & $6.98 E-09$ & & & & & NN & Yes & Yes \\
\hline 25 & $4.43 E-08$ & $1.58 E-08$ & $1.94 E-05$ & 0.9206 & 0.4082 & IN & $\mathrm{IN}^{* *}$ & $\mathrm{IN}^{* *}$ & & & & \\
\hline 26 & 0.8385 & 0.7831 & 0.8926 & 0.9465 & $2.51 E-16$ & & & & & $I N+L D$ & & Yes \\
\hline 28 & 0.0016 & $1.70 E-08$ & 0.0008 & $2.21 E-13$ & 0.0002 & LD* NS & $L D^{*} N S$ & $\mathrm{LD}^{*} \mathrm{NS}$ & $\mathrm{IN}^{*}+\mathrm{LD}$ & $L D^{*}$ & Yes & Yes \\
\hline 29 & $8.09 E-07$ & $2.03 E-07$ & 0.0007 & 0.7631 & $3.02 E-05$ & $I N+L D$ & $I N+L D$ & $I N+L D$ & & NN & & Yes \\
\hline 31 & 0.1197 & 0.0159 & 0.1152 & 0.0773 & $3.15 E-05$ & & IN & & & $\mathrm{IN}^{* *}$ & Yes & Yes \\
\hline 32 & $9.08 E-09$ & $3.95 E-08$ & 0.0001 & 0.5293 & $4.20 E-07$ & LD NS & NN & LD & & $I N+L D$ & & \\
\hline
\end{tabular}

CNV27, CNV33 to CNV37 were not considered due to their large sizes ( $>400 \mathrm{~kb}$ ). For CNVs less than 400 kb in length, their $\mathrm{p}$ values $<0.05$ after FDR correction were shown in bold and italic. For the meanings of $\mathrm{IN}^{*}, \mathrm{IN}^{* *}, \mathrm{LD}^{*}$, please refer to the main text. 
Table 2 Pairwise Pearson correlation coefficients for all pairs of traits

\begin{tabular}{lccccc}
\hline & $\begin{array}{c}\text { Milk } \\
\text { Yield }\end{array}$ & $\begin{array}{c}\text { Fat } \\
\text { Yield }\end{array}$ & $\begin{array}{c}\text { Protein } \\
\text { Yield }\end{array}$ & $\begin{array}{c}\text { Fat } \\
\text { Percentage }\end{array}$ & $\begin{array}{c}\text { Protein } \\
\text { Percentage }\end{array}$ \\
\hline Milk Yield & - & 0.7181 & 0.9040 & -0.3285 & -0.3596 \\
Fat Yield & 0.7181 & - & 0.7938 & 0.4206 & 0.0581 \\
Protein Yield & 0.9040 & 0.7938 & - & -0.1012 & 0.0723 \\
Fat Percentage & -0.3285 & 0.4206 & -0.1012 & - & 0.5470 \\
Protein Percentage & -0.3596 & 0.0581 & 0.0723 & 0.5470 & - \\
\hline
\end{tabular}

"LD NS". When a CNV was adjacent to a haploblock which contained no significant SNP, we called it "LD* NS". For complicated situation where both "IN" and "LD" existed, "IN" was considered first and used instead of "LD" as the category. Finally, when a CNV did not overlap with any SNPs and was not in a haploblock, we called it "NN".

\section{Results and discussion}

\section{Trait properties and correlations}

We selected five traits related to milk production for an association analysis: milk yield (MY), fat yield (FY), protein yield (PY), fat percentage (FP), protein percentage (PP). The descriptive statistics of PTA, including reliability and heritability, are given in Additional file 1: Figure S1 and Additional file 2: Figure S2, respectively. Pearson correlation coefficients for all pairs of traits are provided in Table 2. As expected, the three yield traits (MY, FY and PY) are strongly and positively correlated. The two percentage traits (FP and PP) are positively correlated with each other, but are negatively correlated with the yield traits.

\section{CNV segmentation and genotyping}

In contrast to conventional $\mathrm{CNV}$ discovery studies, which try to detect as many variable regions as possible, this CNV-based GWAS is intended to identify the common CNVs shared among samples in order to detect associations with common diseases or traits. Using the multivariate method of CNAM in SVS, a total of 2,626,669 distinct segments were detected in the 26,362 samples. After merging across samples, 99 nonredundant CNVs were left for subsequent association test (Additional file 3: Table S1). Within these 99 segments, each sample was genotyped (i.e., called as loss, neutral or gain event) according to a threestate model with strict threshold levels of marker mean \pm 0.5. Since the multivariate CNAM method was developed to identify common CNVs, only those segments with frequencies above $0.4 \%$ were retained for further analysis in order to filter away false positive calls. A total of $39 \mathrm{CNVs}$ ranging in size from $45,109 \mathrm{bp}$ to $7.16 \mathrm{Mb}$ were retained (frequency $>0.04$ ). These $39 \mathrm{CNVs}$ have an estimated average size and SNP count of $962.71 \mathrm{~kb}$ and 18.4, respectively.

\section{CNV association analyses}

A total of 26,362 Holstein cattle were employed to test associations between CNVs and dPTA data. Using a linear regression, we identified a total of $34 \mathrm{CNVs}$ that were significantly associated with at less one trait (Figure 1 and

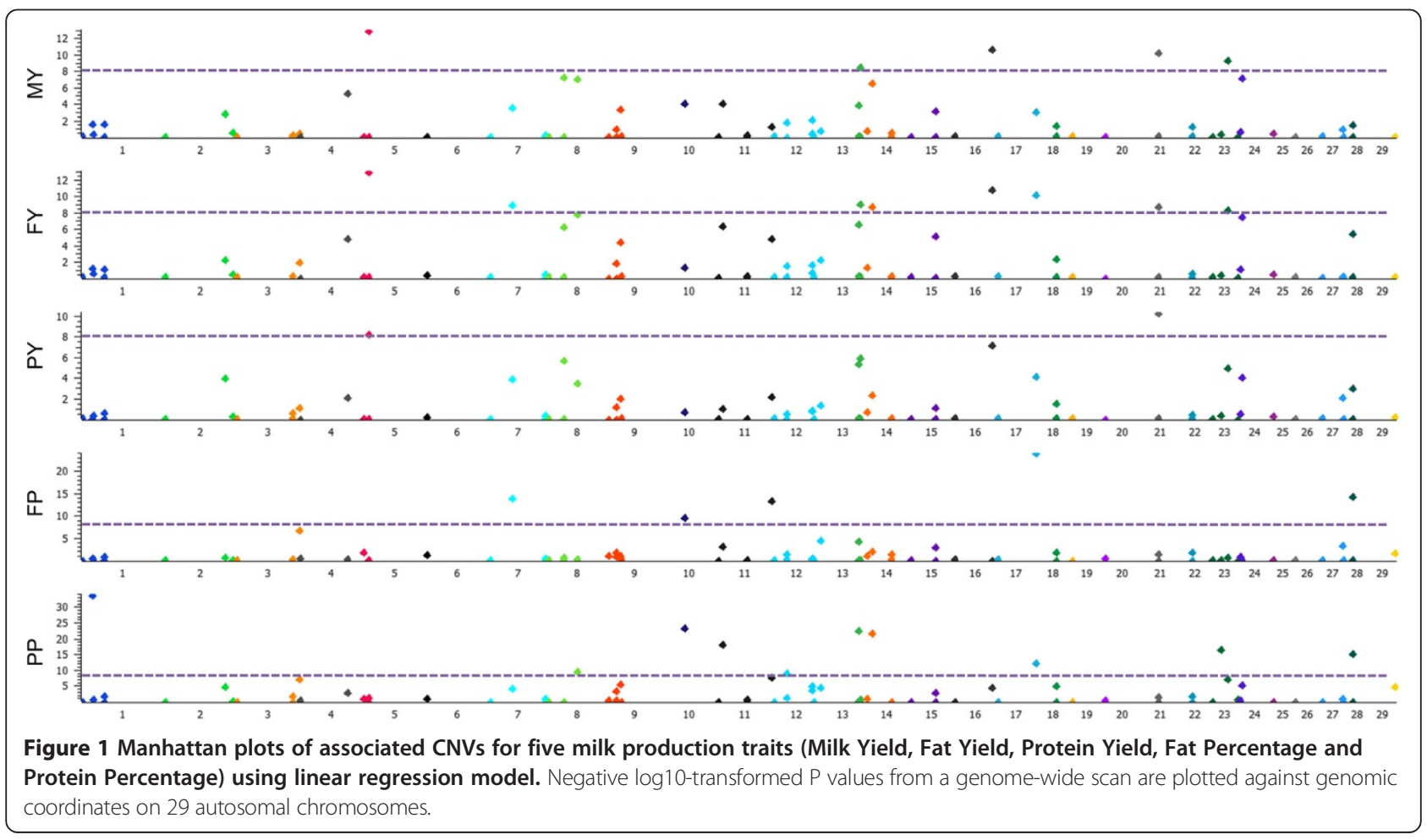


Additional file 4: Table S2). Among those 34 associated CNVs, the CNV with the highest frequency (96.03\%) was found at chr14:11,250,157-11,307,423, while the CNV with the lowest frequency $(2.09 \%)$ was localized at chr29:46,099,425-51,502,868 (Additional file 4: Table S2). After we removed $6 \mathrm{CNVs}$ larger than $400 \mathrm{~kb}$ (CNV27, CNV33 to CNV37), we compared the 28 remaining CNVs with 5 previously published results $[23,26,27,45,46]$. We found 23 out of these 28 CNVs (82.1\%) were also previously reported, and the 5 non-overlapping CNVs (CNV4, 5, 8, 9 and 23) had high frequencies (ranging from 30 to $70 \%$ ) and large marker mean changes (ranging from -0.56 to -1.31 , deviated from 0 ), suggesting they are probably real CNVs. Three CNVs: CNV6 (chr13:70,496,054-70,623,303), CNV28 (chr7:42,700,42542,788,788), and CNV33 (chr17:73,055,503-75,058,715) had $\mathrm{P}$ values $<0.05$ after FDR correction for all five traits. Their frequencies were $66.88 \%, 16.95 \%$ and $7.55 \%$, respectively (Additional file 4: Table S2). Another 12 CNVs were significantly associated with four traits. The overlapping relationship of these associated CNVs among 5 traits was shown in a Venn diagram (Additional file 5: Figure S3).

We then overlapped these 34 associated CNVs with the reported cattle QTL as reported by the Animal QTL database at http://www.animalgenome.org/QTLdb/cattle.html [47]. When considered together, 21 of the 34 significant CNVs overlapped with at least one of the known QTL for milk production. Among these $34 \mathrm{CNVs}$, we found 15, 15, 14, 7 and 6 CNVs overlapping with QTL for MY, FY, PY, FP and PP traits, respectively (Additional file 4: Table S2). Based on the UMD 3.1 assembly, Additional file 4: Table S2 summarizes these 34 CNV regions, bovine RefSeq gene annotations within the CNV regions (1X), and flanking regions (3X: extended regions by one $\mathrm{CNV}$ length in both downstream and upstream directions).

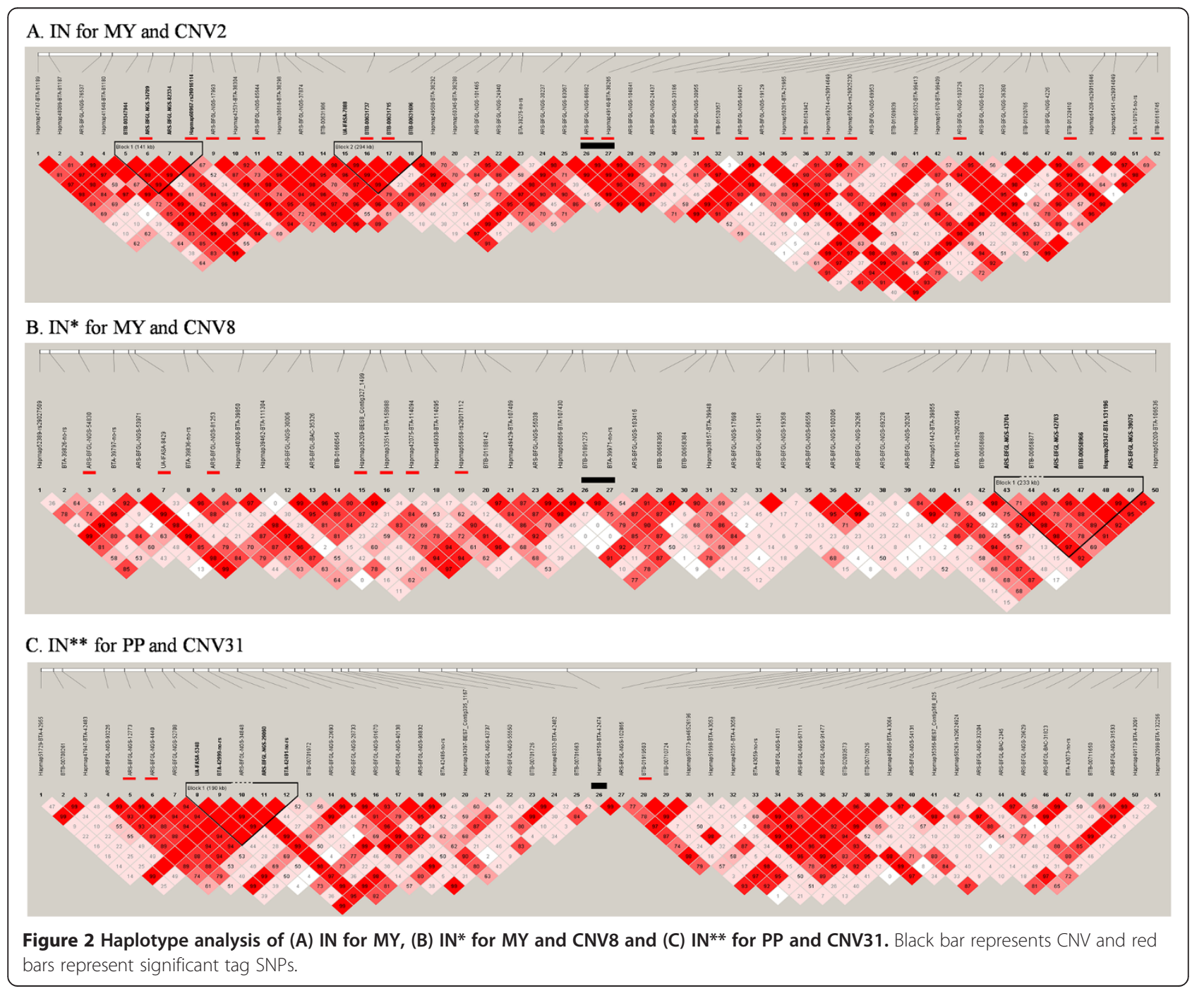




\section{CNVs significantly associated with milk traits}

Of the 34 CNVs, 19, 23 and 18 were significantly associated with MY, FY and PY, respectively (Additional file 4: Table S2). Taken together, $15 \mathrm{CNVs}$ were significantly associated with all three yield traits. One top-ranked CNV, CNV10 (chr5:9,756,491-9,837,147), reached significance values of $9.66 \times 10^{-12}, 8.38 \times 10^{-12}$ and $2.23 \times$ $10^{-7}$ for MY, FY, and PY, respectively. In the proximity of this region, two QTL effect peaks were reported at the 1 to $3 \mathrm{cM}$ region of chr 5 for milk traits in Holstein cattle using SNP data [11]. On chr14, we identified CNV1 (chr14:11,250,157-11,307,423) starting from SNP Hapmap29947-BTC-070181, near the previously reported milk production QTL regions. This CNV had the highest frequency $(96.03 \%)$ and is 57,267 bp long. Approximately $6 \mathrm{Mb}$ upstream of this $\mathrm{CNV}$ segment, the NIBP gene has been reported to also have highly significant effect for milk yield $[8,48]$. Several important genes located further upstream, including DGAT1 and VPS28, have been validated to have highly significant effects for milk production traits $[12,49]$. Within the gene cluster including DGAT1 and NIBP, our previous SNP-based study using U.S. Holstein cows also identified some SNPs, which are significantly associated with effects on milk production trait [8].

We also identified 11 and $29 \mathrm{CNVs}$ that were significantly associated with FP and PP, respectively. The most significant $\mathrm{CNV}$ associated with FP was CNV33 (chr17:73, $055,503-75,058,715)$ with a p-value of $\left.7.00 \times 10^{-23}\right)$. We also found other CNVs like CNV12, CNV18, CNV28 and
CNV34. However, CNV28 overlaps with only one QTL previously reported on chr7 [50]. Using PP, we identified the largest number (23) of significantly associated CNVs. Eleven of them were also significantly associated with all three yield traits (Table 1 and Additional file 5: Figure S3). The top five CNVs were CNV3, CNV6, CNV1, CNV12 and CNV9 based on their p values of the association test. QTL evidence from previous studies were also found in CNV1 [50-52], CNV24 [53], CNV26 [53,54] CNV36 [55] and CNV37 [56-58].

\section{Relationship between associated CNVs and associated SNPs}

To further explore the relationship between SNPs and CNVs, we carried out association tests based on SNPs using the same 26,362 Holstein cattle SNP array data. Additional file 6: Table S3 contains SNP information near CNV regions. For all 82 possible combinations of traits and CNVs (less than $400 \mathrm{~kb}$ in length), we found 17 cases where significant SNPs directly overlapped with CNVs (e.g. IN for MY and CNV2, Figure 2A), 26 cases where significant SNPs were directly adjacent to $\mathrm{CNVs}$ (IN* for MY and CNV8, Figure 2B), and 14 cases where significant SNPs are the second SNPs next to CNVs (IN** for PP and CNV31, Figure 2C). To determine if there is any linkage between $\mathrm{CNVs}$ and neighboring SNPs, we performed LD analysis by computing pairwise D' around CNV regions which included 25 SNPs both downstream and upstream of associated CNVs. Our results showed three cases (LD for FY and CNV18, Figure 3A) where CNVs were enclosed in the same haplotype block

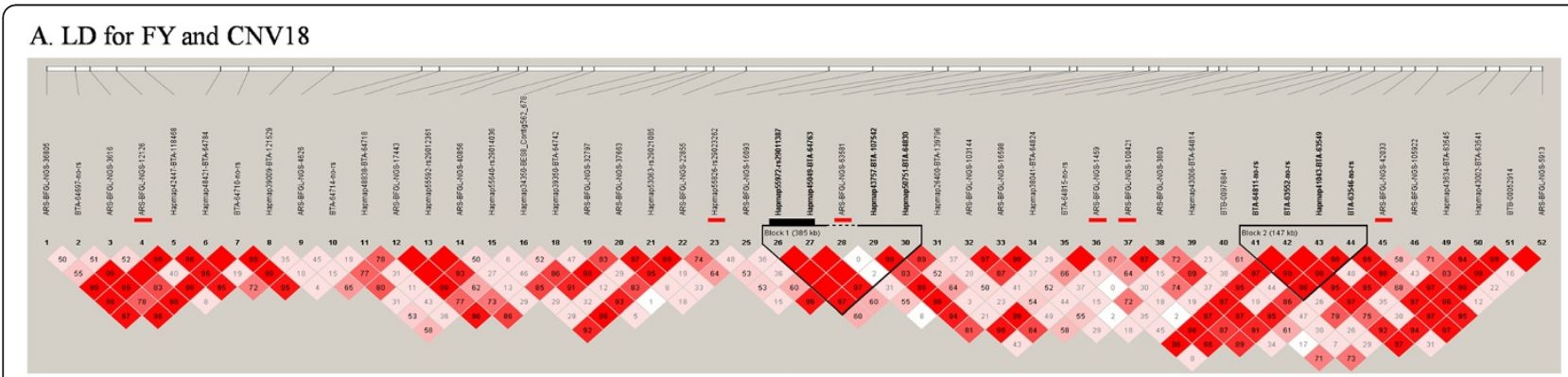

B. LD* for FP and CNV16

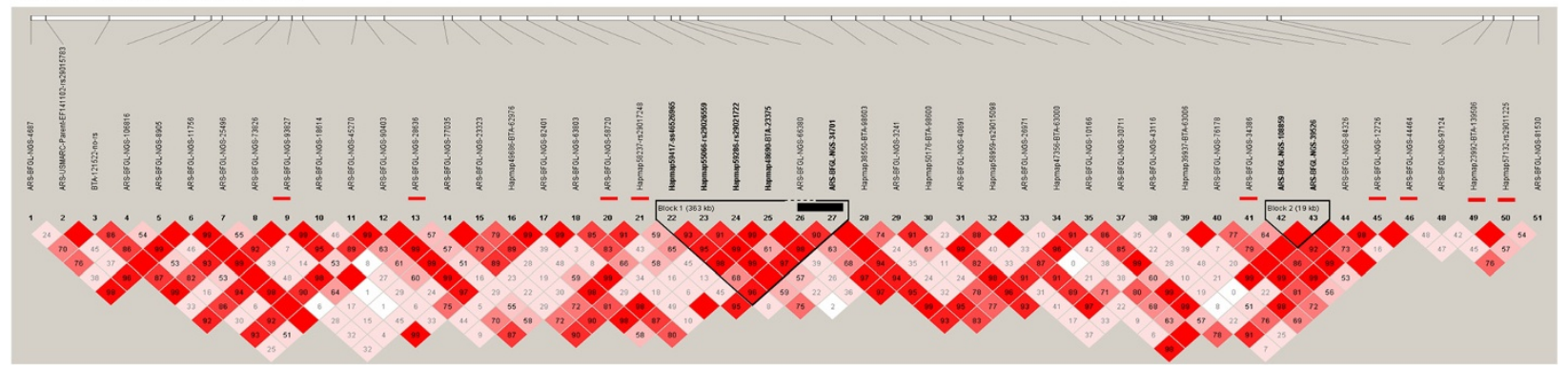

Figure 3 Haplotype analysis of (A) LD for FY and CNV18 and (B) LD* for FP and CNV16. Black bar represents CNV and red bars represent significant tag SNPS. 
Table 3 Summary of relationship between CNVs and SNPs

\begin{tabular}{|c|c|c|c|c|c|c|c|c|c|c|c|c|}
\hline & \multicolumn{2}{|c|}{ MY } & \multicolumn{2}{|c|}{$\mathrm{FY}$} & \multicolumn{2}{|c|}{ PY } & \multicolumn{2}{|c|}{$\mathrm{FP}$} & \multicolumn{2}{|c|}{ PP } & \multicolumn{2}{|c|}{ All } \\
\hline & Count & $\%$ & Count & $\%$ & Count & $\%$ & Count & $\%$ & Count & $\%$ & Count & $\%$ \\
\hline $\mathrm{NN}$ & 2 & $11.76 \%$ & 2 & $10.53 \%$ & 2 & $12.50 \%$ & 2 & $28.57 \%$ & 8 & $34.78 \%$ & 16 & $19.51 \%$ \\
\hline LD NS & 2 & $11.76 \%$ & 1 & $5.26 \%$ & 1 & $6.25 \%$ & 0 & $0.00 \%$ & 0 & $0.00 \%$ & 4 & $4.88 \%$ \\
\hline Not tagged & 4 & $23.53 \%$ & 3 & $15.79 \%$ & 3 & $18.75 \%$ & 2 & $28.57 \%$ & 8 & $34.78 \%$ & 20 & $24.39 \%$ \\
\hline LD & 0 & $0.00 \%$ & 1 & $5.26 \%$ & 2 & $12.50 \%$ & 0 & $0.00 \%$ & 0 & $0.00 \%$ & 3 & $3.66 \%$ \\
\hline$L D^{*}$ & 0 & $0.00 \%$ & 0 & $0.00 \%$ & 0 & $0.00 \%$ & 1 & $14.29 \%$ & 1 & $4.35 \%$ & 2 & $2.44 \%$ \\
\hline IN & 4 & $23.53 \%$ & 4 & $21.05 \%$ & 3 & $18.75 \%$ & 0 & $0.00 \%$ & 6 & $26.09 \%$ & 17 & $20.73 \%$ \\
\hline $\mathrm{IN}^{*}$ & 6 & $35.29 \%$ & 5 & $26.32 \%$ & 5 & $31.25 \%$ & 4 & $57.14 \%$ & 6 & $26.09 \%$ & 26 & $31.71 \%$ \\
\hline $\mathrm{IN}^{* *}$ & 3 & $17.65 \%$ & 6 & $31.58 \%$ & 3 & $18.75 \%$ & 0 & $0.00 \%$ & 2 & $8.70 \%$ & 14 & $17.07 \%$ \\
\hline Tagged & 13 & $76.47 \%$ & 16 & $84.21 \%$ & 13 & $81.25 \%$ & 5 & $71.43 \%$ & 15 & $65.22 \%$ & 62 & $75.61 \%$ \\
\hline Total & 17 & & 19 & & 16 & & 7 & & 23 & & 82 & \\
\hline
\end{tabular}

For the meanings of $\mathrm{IN}^{*}, \mathrm{IN}^{* *}, \mathrm{LD}^{*}$, please refer to the main text.

with at least one significant SNP, two cases where CNVs were directly adjacent to a haploblock which contains at least one significant SNP (LD* for FP and CNV16, Figure 3B), which suggested these CNVs could be represented by tagged SNPs within the same haploblock.

Some cases were complex situations involving both IN and LD. We generally assigned them to the IN, IN* and $\mathrm{IN}^{* *}$ instead of LD or LD* classes. However, no matter which class was used, CNVs in both the IN and LD classes were apparently well-captured by neighboring tag SNPs. It is interesting to note that although 9 out of 31 CNVs were located within breakpoints of haploblocks (Table 1 and Additional file 7: Figure S4), 7 of them were still tagged by neighboring SNPs. For example, we found one haploblock from Hapmap55972-rs29011387 to Hapmap50751-BTA-64830 in CNV28 with a length of $385 \mathrm{~kb}$. We observed one SNP ARS-BFGL-NGS-63581 which was significantly associated with MY, FY, and PY (Additional file 7: Figure S4). We obtained one haploblock from Hapmap54599-rs29019617 to Hapmap48210-BTA120730 in CNV21 and one SNPs Hapmap48210-BTA120730 were detected to associate with MY, FY, PY and PP. For CNV32, one haploblock from ARS-BFGL-NGS-
109612 to ARS-BFGL-NGS-26195 that contained a PYassociated SNP INRA-655 was identified. For CNV26, one large region containing three adjacent haploblocks (161 kb, $286 \mathrm{~kb}, 85 \mathrm{~kb}$ ), which ranged from ARS-BFGLBAC-28908 to ARS-BFGL-NGS-501, was found. These regions contained many SNPs associated with production traits. Additionally, two adjacent haploblocks were detected near CNV4, from ARS-BFGL-NGS-234 to ARS-BFGL-NGS-35131. This region contains one SNP ARS-BFGL-NGS-102090, which was significantly associated with MY, FY, and PY. Moreover, three adjacent haploblocks were found near CNV 28 (from ARS-BFGL-NGS-100845 to ARS-BFGL-NGS-13798), several significant associated SNPs were also found in this region.

Finally, we also found 20 cases where CNVs were not related (overlapping, neighboring or LD) with significantly associated SNPs (Table 3), suggesting that the impacts of those CNVs were probably not captured (e.g., $\mathrm{NN}$ for PP and CNV6, Figure 4. For more examples, please see Additional file 7: Figure S4). The possibility for this observation is that CNVs are likely to work as independent variants besides SNP. For example, we indentified a haploblock embedded in CNV16, which spanned

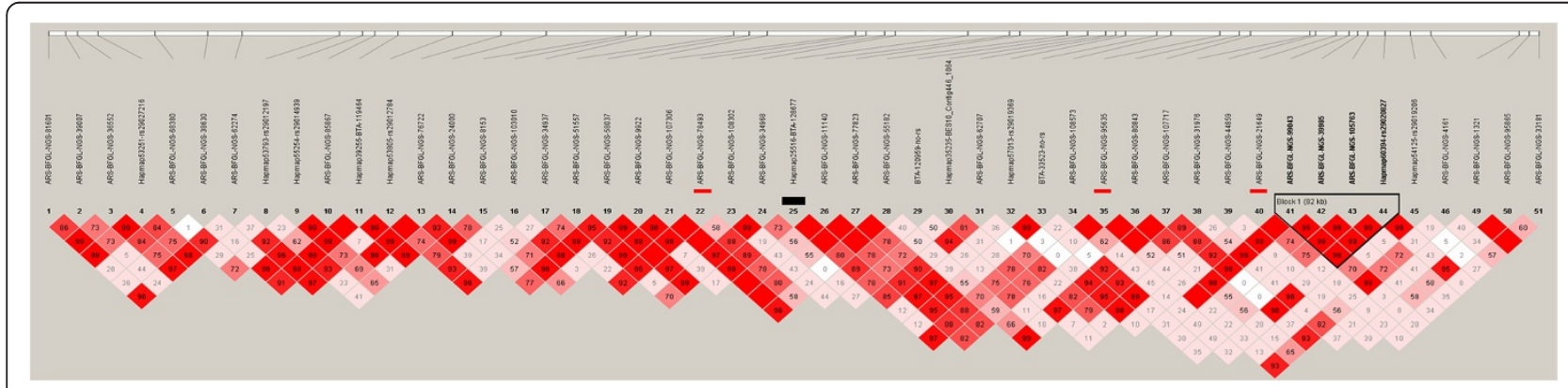

Figure 4 Haplotype analysis of NN for PP and CNV6. Black bar represents CNV and red bars represent significant tag SNPS. 
$363 \mathrm{~kb}$ on chr27. However, no significant associated SNPs were found in this haploblock region for PY.

\section{Conclusions}

Previous and current genome wide association studies have been investigated to identify significant genes or linked markers based on SNPs. In this CNV-based study, our results indicate that $\mathrm{CNV}$ are associated with, and likely contribute to, differences in milk production. Our study provides a systematic estimate that approximately one-quarter of CNVs are not captured by LD with nearby SNPs. This provides an alternative framework to explain the missing heritability of complex traits. This study helps to fill gaps left by current SNP-based genome wide association and selection studies. Therefore, we conclude that combining CNV with SNP analyses reveals more genetic variations underlying milk production traits than can be revealed by SNPs alone. Interrogation of the genome for both CNVs and SNPs, including common and rare variations, could be an effective way to identify the causes of complex diseases and traits $[16,59]$. A more comprehensive appreciation of the full spectrum of genetic variation may unravel the genetic basis for milk production.

\section{Availability of supporting data}

Supporting information is available in the additional files and further supporting data is available from the authors on request.

\section{Additional files}

Additional file 1: Figure S1. Boxplot of reliability of five production traits. Additional file 2: Figure S2. Heritability of five production traits.

Additional file 3: Table S1. List of CNV segments.

Additional file 4: Table S2. Cattle QTL and RefSeq genes of 34 CNVs based on the UMD 3.1 assembly.

Additional file 5: Figure S3. Overlapping relationships of 34 significantly associated CNV segments among five milk production traits.

Additional file 6: Table S3. SNPs near CNV regions.

Additional file 7: Figure S4. Haplotype block views.

\section{Competing interests}

The authors declare that they have no competing interests.

\section{Authors' contributions}

GEL and LX conceived and designed the experiments. $L X, Y H, D M B$, JS and GEL performed in silico prediction and computational analyses. JBC, PMV, TSS and CPVT collected the phenotypic and genotypic data. GEL, LX, and JBC wrote the paper. All authors read and approved the final manuscript.

\section{Acknowledgements}

We thank Reuben Anderson and Alexandre Dimitriv for technical assistance. This work was supported in part by AFRI grant No. 2011-67015-30183 from USDA NIFA. Mention of trade names or commercial products in this article is solely for the purpose of providing specific information and does not imply recommendation or endorsement by the US Department of Agriculture. The USDA is an equal opportunity provider and employer.

\section{Author details}

Animal Genomics and Improvement Laboratory, BARC, USDA-ARS, Beltsville, Maryland 20705, USA. '2Department of Animal and Avian Sciences, University of Maryland, College Park, Maryland 20742, USA. ${ }^{3}$ Beijing Institute of Genomics, Chinese Academy of Sciences, Beijing 100029, China.

Received: 24 March 2014 Accepted: 31 July 2014

Published: 15 August 2014

\section{References}

1. Schnabel RD, Kim JJ, Ashwell MS, Sonstegard TS, Van Tassell CP, Connor EE, Taylor JF: Fine-mapping milk production quantitative trait loci on BTA6: analysis of the bovine osteopontin gene. Proc Natl Acad Sci U S A 2005, 102:6896-6901.

2. Gautier M, Barcelona RR, Fritz S, Grohs C, Druet T, Boichard D, Eggen A, Meuwissen THE: Fine mapping and physical characterization of two linked quantitative trait loci affecting milk fat yield in dairy cattle on BTA26. Genetics 2006, 172:425-436.

3. Grisart B, Coppieters W, Farnir F, Karim L, Ford C, Berzi P, Cambisano N, Mni M, Reid S, Simon P, Spelman R, Georges M, Snell R: Positional candidate cloning of a QTL in dairy cattle: Identification of a missense mutation in the bovine DGAT1 gene with major effect on milk yield and composition. Genome Res 2002, 12:222-231.

4. Cohen-Zinder M, Seroussi E, Larkin DM, Loor JJ, Everts-van der Wind A, Lee JH, Drackley JK, Band MR, Hernandez AG, Shani M, Lewin HA, Weller Jl, Ron M: Identification of a missense mutation in the bovine ABCG2 gene with a major effect on the QTL on chromosome 6 affecting milk yield and composition in Holstein cattle. Genome Res 2005, 15:936-944.

5. Jiang L, Liu JF, Sun DX, Ma PP, Ding XD, Yu Y, Zhang Q: Genome Wide Association Studies for Milk Production Traits in Chinese Holstein Population. Plos One 2010, 5:e13661.

6. Meredith BK, Kearney FJ, Finlay EK, Bradley DG, Fahey AG, Berry DP, Lynn DJ: Genome-wide associations for milk production and somatic cell score in Holstein-Friesian cattle in Ireland. BMC Genet 2012, 13:21.

7. Maxa J, Neuditschko M, Russ I, Forster M, Medugorac I: Genome-wide association mapping of milk production traits in Braunvieh cattle. J Dairy Sci 2012, 95:5357-5364.

8. Cole JB, Wiggans GR, Ma L, Sonstegard TS, Lawlor TJ Jr, Crooker BA, Van Tassell CP, Yang J, Wang S, Matukumalli LK, Da Y: Genome-wide association analysis of thirty one production, health, reproduction and body conformation traits in contemporary U.S. Holstein cows. BMC Genomics 2011, 12:408

9. Wang XL, Wurmser C, Pausch H, Jung S, Reinhardt F, Tetens J, Thaller G, Fries R: Identification and Dissection of Four Major QTL Affecting Milk Fat Content in the German Holstein-Friesian Population. Plos One 2012, 7 doi:10.1371/journal.pone.0040711.

10. Kolbehdari D, Wang Z, Grant JR, Murdoch B, Prasad A, Xiu Z, Marques E, Stothard P, Moore SS: A whole genome scan to map QTL for milk production traits and somatic cell score in Canadian Holstein bulls. J Anim Breed Genet 2009, 126:216-227.

11. Daetwyler HD, Schenkel FS, Sargolzaei M, Robinson JAB: A genome scan to detect quantitative trait loci for economically important traits in Holstein cattle using two methods and a dense single nucleotide polymorphism map. J Dairy Sci 2008, 91:3225-3236.

12. Winter A, Kramer W, Werner FAO, Kollers S, Kata S, Durstewitz G, Buitkamp J, Womack JE, Thaller G, Fries R: Association of a lysine-232/alanine polymorphism in a bovine gene encoding acyl-CoA : diacylglycerol acyltransferase (DGAT1) with variation at a quantitative trait locus for milk fat content. Proc Natl Acad Sci U S A 2002, 99:9300-9305.

13. Grisart B, Farnir F, Karim L, Cambisano N, Kim JJ, Kvasz A, Mni M, Simon P, Frere JM, Coppieters W, Georges M: Genetic and functional confirmation of the causality of the DGAT1 K232A quantitative trait nucleotide in affecting milk yield and composition. Proc Natl Acad Sci U S A 2004, 101:2398-2403.

14. Viitala S, Szyda J, Blott S, Schulman N, Lidauer M, Maki-Tanila A, George M, Vilkki J: The role of the bovine growth hormone receptor and prolactin receptor genes in milk, fat and protein production in Finnish Ayrshire dairy cattle. Genetics 2006, 173:2151-2164.

15. Blott S, Kim JJ, Moisio S, Schmidt-Kuntzel A, Cornet A, Berzi P, Cambisano N, Ford C, Grisart B, Johnson D, Karim L, Simon P, Snell R, Spelman R, Wong J, Vilkki J, Georges M, Farnir F, Coppieters W: Molecular dissection of a 
quantitative trait locus: A phenylalanine-to-tyrosine substitution in the transmembrane domain of the bovine growth hormone receptor is associated with a major effect on milk yield and composition. Genetics 2003, 163:253-266.

16. Manolio TA, Collins FS, Cox NJ, Goldstein DB, Hindorff LA, Hunter DJ, McCarthy MI, Ramos EM, Cardon LR, Chakravarti A, Cho JH, Guttmacher AE, Kong A, Kruglyak L, Mardis E, Rotimi CN, Slatkin M, Valle D, Whittemore AS, Boehnke M, Clark AG, Eichler EE, Gibson G, Haines JL, Mackay TF, McCarroll SA, Visscher PM: Finding the missing heritability of complex diseases. Nature 2009, 461:747-753.

17. Scherer SW, Lee C, Birney E, Altshuler DM, Eichler EE, Carter NP, Hurles ME, Feuk $L$ : Challenges and standards in integrating surveys of structural variation. Nat Genet 2007, 39:S7-15.

18. Zhang F, Gu W, Hurles ME, Lupski JR: Copy number variation in human health, disease, and evolution. Annu Rev Genomics Hum Genet 2009, 10:451-481.

19. Stranger BE, Forrest MS, Dunning M, Ingle CE, Beazley C, Thorne N, Redon R, Bird CP, de Grassi A, Lee C, Tyler-Smith C, Carter N, Scherer SW, Tavare S, Deloukas P, Hurles ME, Dermitzakis ET: Relative impact of nucleotide and copy number variation on gene expression phenotypes. Science 2007, 315:848-853.

20. Henrichsen CN, Vinckenbosch N, Zollner S, Chaignat E, Pradervand S, Schutz F, Ruedi M, Kaessmann H, Reymond A: Segmental copy number variation shapes tissue transcriptomes. Nat Genet 2009, 41:424-429.

21. Liu GE, Hou Y, Zhu B, Cardone MF, Jiang L, Cellamare A, Mitra A, Alexander L, Coutinho LL, Dell'Aquila ME, Gasbarre LC, Lacalandra G, Li RW, Matukumalli LK, Nonneman D, Regitano LC, Smith TP, Song J, Sonstegard TS, Van Tassell CP, Ventura M, Eichler EE, McDaneld TG, Keele JW: Analysis of copy number variations among diverse cattle breeds. Genome Res 2010, 20:693-703.

22. Bae JS, Cheong HS, Kim LH, NamGung S, Park TJ, Chun JY, Kim JY, Pasaje CFA, Lee JS, Shin HD: Identification of copy number variations and common deletion polymorphisms in cattle. BMC Genomics 2010, 11:232.

23. Hou Y, Liu GE, Bickhart DM, Cardone MF, Wang K, Kim ES, Matukumalli LK, Ventura M, Song J, VanRaden PM, Sonstegard TS, Van Tassell CP: Genomic characteristics of cattle copy number variations. BMC Genomics 2011, 12:127.

24. Choi JW, Lee KT, Liao XP, Stothard P, An HS, Ahn S, Lee S, Lee SY, Moore SS, Kim TH: Genome-wide copy number variation in Hanwoo, Black Angus, and Holstein cattle. Mamm Genome 2013, 24:151-163.

25. Cicconardi F, Chillemi G, Tramontano A, Marchitelli C, Valentini A, AjmoneMarsan $P$, Nardone A: Massive screening of copy number populationscale variation in Bos taurus genome. BMC Genomics 2013, 14:124.

26. Hou Y, Bickhart DM, Hvinden ML, Li C, Song J, Boichard DA, Fritz S, Eggen A, DeNise S, Wiggans GR, Sonstegard TS, Van Tassell CP, Liu GE: Fine mapping of copy number variations on two cattle genome assemblies using high density SNP array. BMC Genomics 2012, 13:376.

27. Jiang L, Jiang JC, Yang J, Liu X, Wang JY, Wang HF, Ding XD, Liu JF, Zhang Q: Genome-wide detection of copy number variations using high-density SNP genotyping platforms in Holsteins. BMC Genomics 2013, 14:131.

28. Bickhart DM, Hou Y, Schroeder SG, Alkan C, Cardone MF, Matukumalli LK, Song J, Schnabel RD, Ventura M, Taylor JF, Garcia JF, Van Tassell CP, Sonstegard TS, Eichler EE, Liu GE: Copy number variation of individual cattle genomes using next-generation sequencing. Genome Res 2012, 22:778-790.

29. Fadista J, Thomsen B, Holm LE, Bendixen C: Copy number variation in the bovine genome. BMC Genomics 2010, 11:284.

30. Seroussi E, Glick G, Shirak A, Yakobson E, Weller J, Ezra E, Zeron Y: Analysis of copy loss and gain variations in Holstein cattle autosomes using BeadChip SNPs. BMC Genomics 2010, 11:673.

31. Zhang L, Jia S, Yang M, Xu Y, Li C, Sun J, Huang Y, Lan X, Lei C, Zhou Y, Zhang $C$, Zhao $X$, Chen $H$ : Detection of copy number variations and their effects in Chinese bulls. BMC Genomics 2014, 15:480.

32. Hou Y, Liu GE, Bickhart DM, Matukumalli LK, Li C, Song J, Gasbarre LC, Van Tassell CP, Sonstegard TS: Genomic regions showing copy number variations associate with resistance or susceptibility to gastrointestinal nematodes in Angus cattle. Funct Integr Genomics 2012, 12:81-92.

33. Hou Y, Bickhart DM, Chung H, Hutchison JL, Norman HD, Connor EE, Liu GE: Analysis of copy number variations in Holstein cows identify potential mechanisms contributing to differences in residual feed intake. Funct Integr Genomics 2012, 12:717-723.

34. Glick G, Shirak A, Seroussi E, Zeron Y, Ezra E, Weller Jl, Ron M: Fine Mapping of a QTL for Fertility on BTA7 and Its Association With a CNV in the Israeli Holsteins. G3 (Bethesda) 2011, 1:65-74.
35. Kadri NK, Sahana G, Charlier C, Iso-Touru T, Guldbrandtsen B, Karim L, Nielsen US, Panitz F, Aamand GP, Schulman N, Georges M, Vilkki J, Lund MS, Druet T: A 660-kb deletion with antagonistic effects on fertility and milk production segregates at high frequency in nordic red cattle: additional evidence for the common occurrence of balancing selection in livestock. PLoS Genet 2014, 10:e1004049.

36. Kadri NK, Koks PD, Meuwissen TH: Prediction of a deletion copy number variant by a dense SNP panel. Genet Sel Evol 2012, 44:7.

37. VanRaden PM, Van Tassell CP, Wiggans GR, Sonstegard TS, Schnabel RD, Taylor JF, Schenkel FS: Invited review: Reliability of genomic predictions for North American Holstein bulls. J Dairy Sci 2009, 92:16-24.

38. Wiggans GR, Sonstegard TS, Vanraden PM, Matukumalli LK, Schnabel RD, Taylor JF, Schenkel FS, Van Tassell CP: Selection of single-nucleotide polymorphisms and quality of genotypes used in genomic evaluation of dairy cattle in the United States and Canada. J Dairy Sci 2009, 92:3431-3436.

39. Vanraden PM, Wiggans GR: Derivation, Calculation, and Use of National Animal-Model Information. J Dairy Sci 1991, 74:2737-2746.

40. Garrick DJ, Taylor JF, Fernando RL: Deregressing estimated breeding values and weighting information for genomic regression analyses. Genet Sel Evol 2009, 41:1.

41. Xu L, Hou Y, Bickhart DM, Song J, Van Tassell CP, Sonstegard TS, Liu GE: A genome-wide survey reveals a deletion polymorphism associated with resistance to gastrointestinal nematodes in Angus cattle. Funct Integr Genomics 2014, 14:333-339.

42. Barrett JC, Fry B, Maller J, Daly MJ: Haploview: analysis and visualization of LD and haplotype maps. Bioinformatics 2005, 21:263-265.

43. Gabriel SB, Schaffner SF, Nguyen H, Moore JM, Roy J, Blumenstiel B, Higgins J, DeFelice M, Lochner A, Faggart M, Liu-Cordero SN, Rotimi C, Adeyemo A, Cooper R, Ward R, Lander ES, Daly MJ, Altshuler D: The structure of haplotype blocks in the human genome. Science 2002, 296:2225-2229.

44. Qanbari S, Pimentel EC, Tetens J, Thaller G, Lichtner P, Sharifi AR, Simianer H: The pattern of linkage disequilibrium in German Holstein cattle. Anim Genet 2010, 41:346-356.

45. Zhan B, Fadista J, Thomsen B, Hedegaard J, Panitz F, Bendixen C: Global assessment of genomic variation in cattle by genome resequencing and high-throughput genotyping. BMC Genomics 2011, 12:557.

46. Jiang L, Jiang JC, Wang JY, Ding XD, Liu JF, Zhang Q: Genome-Wide Identification of Copy Number Variations in Chinese Holstein. Plos One 2012, 7:e48732.

47. Hu ZL, Park CA, Wu XL, Reecy JM: Animal QTLdb: an improved database tool for livestock animal QTL/association data dissemination in the post-genome era. Nucleic Acids Res 2013, 41:D871-D879.

48. Ma L, Wiggans GR, Wang S, Sonstegard TS, Yang J, Crooker BA, Cole JB, Van Tassell CP, Lawlor TJ, Da Y: Effect of sample stratification on dairy GWAS results. BMC Genomics 2012, 13:536.

49. Thaller G, Kramer W, Winter A, Kaupe B, Erhardt G, Fries R: Effects of DGAT1 variants on milk production traits in German cattle breeds. J Anim Sci 2003, 81:1911-1918.

50. Boichard D, Grohs C, Bourgeois F, Cerqueira F, Faugeras R, Neau A, Rupp R, Amigues $Y$, Boscher MY, Leveziel $\mathrm{H}$ : Detection of genes influencing economic traits in three French dairy cattle breeds. Genet Sel Evol 2003, 35:77-101.

51. Kaupe B, Brandt $H$, Prinzenberg EM, Erhardt G: Joint analysis of the influence of CYP11B1 and DGAT1 genetic variation on milk production, somatic cell score, conformation, reproduction, and productive lifespan in German Holstein cattle. J Anim Sci 2007, 85:11-21.

52. Bennewitz J, Reinsch N, Grohs C, Leveziel H, Malafosse A, Thomsen H, Xu N, Looft C, Kuhn C, Brockmann GA, Schwerin M, Weimann C, Hiendleder S, Erhardt G, Medjugorac I, Russ I, Forster M, Brenig B, Reinhardt F, Reents R, Averdunk G, Blumel J, Boichard D, Kalm E: Combined analysis of data from two granddaughter designs: A simple strategy for QTL confirmation and increasing experimental power in dairy cattle. Genet Sel Evol 2003, 35:319-338.

53. Viitala SM, Schulman NF, de Koning DJ, Elo K, Kinos R, Virta A, Virta J, Maki-Tanila A, Vilkki JH: Quantitative trait loci affecting milk production traits in Finnish Ayrshire dairy cattle. J Dairy Sci 2003, 86:1828-1836.

54. Elo KT, Vilkki J, de Koning DJ, Velmala RJ, Maki-Tanila AV: A quantitative trait locus for live weight maps to bovine chromosome 23. Mamm Genome 1999, 10:831-835.

55. Bagnato A, Schiavini F, Rossoni A, Maltecca C, Dolezal M, Medugorac I, Solkner J, Russo V, Fontanesi L, Friedmann A, Soller M, Lipkin E: 
Quantitative trait loci affecting milk yield and protein percentage in a three-country Brown Swiss population. J Dairy Sci 2008, 91:767-783.

56. Schopen GC, Visker MH, Koks PD, Mullaart E, van Arendonk JA, Bovenhuis H: Whole-genome association study for milk protein composition in dairy cattle. J Dairy Sci 2011, 94:3148-3158.

57. Magee DA, Sikora KM, Berkowicz EW, Berry DP, Howard DJ, Mullen MP, Evans RD, Spillane C, Machugh DE: DNA sequence polymorphisms in a panel of eight candidate bovine imprinted genes and their association with performance traits in Irish Holstein-Friesian cattle. BMC Genet 2010, 11:93

58. Bagnicka E, Siadkowska E, Strzalkowska N, Zelazowska B, Flisikowski K, Krzyzewski J, Zwierzchowski L: Association of polymorphisms in exons 2 and 10 of the insulin-like growth factor 2 ( IGF2) gene with milk production traits in Polish Holstein-Friesian cattle. $J$ Dairy Res 2010, 77:37-42.

59. McCarroll SA: Extending genome-wide association studies to copynumber variation. Hum Mol Genet 2008, 17:R135-R142.

doi:10.1186/1471-2164-15-683

Cite this article as: Xu et al:: Genome wide CNV analysis reveals additional variants associated with milk production traits in Holsteins. BMC Genomics 2014 15:683.

\section{Submit your next manuscript to BioMed Central and take full advantage of:}

- Convenient online submission

- Thorough peer review

- No space constraints or color figure charges

- Immediate publication on acceptance

- Inclusion in PubMed, CAS, Scopus and Google Scholar

- Research which is freely available for redistribution 